\title{
ĐÁNH GIÁ CHẤT LƯợNG GIÁO DỤC ĐẠI HỌC CẤP CƠ Sở GIÁO DỤC THEO TIÊU CHÛ̉N AUN - QA Ở TRƯỜNG ĐẠI HỌC CÔNG NGHIỆP THÀNH PHỐ HỒ CHÍ MINH - THỜI CƠ, THÁĊH THỨC VÀ CÁC GIẢI PHÁP
}

\author{
ĐỖ KHOA THÚY KHA, HUỲNH NGỌC CHÂU \\ Phòng Khảo thí và Đảm bảo chất lương, Trương Đại học Công nghiệp Thành phố Hồ Chí Minh; \\ dokhoathuykha@iuh.edu.vn
}

Tóm tắt. Công tác đảm bảo chất lượng giáo dục ở các cơ sở đào tạo đại học đang nhận được sự quan tâm của toàn xã hội. Trong xu hướng hội nhập quốc tế, Trường Đại học Công nghiệp Thành phố Hồ Chí Minh chủ trương đánh giá chất lượng cấp cơ sở theo tiêu chuẩn AUN - QA. Bài báo này trình bày ngắn gọn về các hoạt động đảm bảo chất lượng tại trường trong thời gian vừa quan, phân tích những khó khăn và thuận lợi khi đánh giá chất lượng theo tiêu chuẩn AUN - QA. Trên cơ sở đó, bài báo cũng đề xuất một số giải pháp nhằm triển khai công tác đảm bảo chất lượng theo tiêu chuẩn $\mathrm{AUN}$ - QA có thể áp dụng tại trường Đại học Công nghiệp Thành phố Hồ Chí Minh. Các giải pháp cơ bản bao gồm: 1 . Thành lập hội đồng đảm bảo chất lượng và tổ thư kí đảm bảo chất lượng; 2 . Xây dựng cơ sở dữ liệu đảm bảo chất lượng chung của toàn trường; 3 . Sử dụng các công cụ triển khai hỗ trợ việc viết báo cáo tự đánh giá; 4 . Tăng cường các hoạt động sử dụng tiếng Anh trong nhà trường.

Keywords: AUN - QA, đảm bảo chất lượng; Trường Đại học Công nghiệp Thành phố Hồ Chí Minh

\section{AUN-QA ASSESSMENT AT INSTITUTIONAL LEVEL AT INDUSTRIAL UNIVERSITY OF HO CHI MINH CITY - OPPORTUNITY, CHALLENGES AND SOLUTIONS}

\begin{abstract}
Quality assurance in higher education institutions is getting the attention of the society. In the trend of international integration, Industrial University of Ho Chi Minh City (IUH) is planing to assess educational quality at institution level in accordance with AUN - QA standards. This article briefly describe quality assurance activities at the university recently time, analyzes the opportunity and difficulties of quality assessment accordance with AUN - QA standards. Based on that, the article also proposed some solutions to implement quality assurance under the AUN - QA standards applicable at IUH. Basic solutions include: 1. Establishing of quality assurance committees and quality assurance secretaries group; 2 . Building a database on quality assurance of the whole university; 3 . Using deployment tools to support selfassessment report writing; 4. Strengthen the use of English in the university.
\end{abstract}

Keywords: AUN - QA, quality assurance, Industrial University of Ho Chi Minh City (IUH)

\section{PHẦN MỞ ĐẦU}

Đảm bảo chất lượng giáo dục đại học là một vấn đề đã và đang được Đảng và nhà nước quan tâm sâu sắc. Điều này thể hiện rõ trong các văn bản của Đảng và Chính phủ. Nghị quyết đại hội Trung ương 8 khóa XI xác định một trong các giải pháp, nhiệm vụ đổi mới căn bản, toàn diện giáo dục là “ Thực hiện đánh giá chất lượng giáo dục, đào tạo ở cấp độ quốc gia, địa phương, từng cơ sở giáo dục, đào tạo và đánh giá theo chương trình của quốc tế để làm căn cứ đề xuất chính sách, giải pháp cải thiện chất lượng giáo dục, đào tạo" và "Hoàn thiện hệ thống kiểm định chất lượng giáo dục. Định kỳ kiểm định chất lượng các cơ sở giáo dục, đào tạo và các chương trình đào tạo; công khai kết quả kiểm định". Luật giáo dục đại học dành một chương để quy định về đảm bảo chất lượng, trong đó quy định rõ cơ sở đào tạo có trách nhiệm: "Thành lập tổ chức chuyên trách về bảo đảm chất lượng giáo dục đại học; Xây dựng và thực hiện kế hoạch bảo đảm chất lượng giáo dục đại học; Tự đánh giá, cải tiến, nâng cao chất lượng đào tạo; định kỳ đăng ký kiểm định chương trình đào tạo và kiểm định cơ sở giáo dục đại học và duy trì và phát triển các điều kiện bảo đảm chất lượng đào tạo". Trên cơ sở các văn bản này, Năm 2007, Bộ Giáo dục đã ban hành quyết định 65/2007/QĐ-BGDĐT ban hành bộ tiêu chuẩn đánh giá chất lượng trường đại học gồm 10 tiêu chuẩn với 61 tiêu chí. Đến năm 2017, để đáp ứng yêu cầu cải thiện liên tục công tác kiểm định chất lượng, Bộ giáo dục đã ban hành thông tư 12/2017/TT-BGDĐT về việc quy định về công tác kiểm định chất lượng giáo dục 
đại học. Trong thông tư này, bộ tiêu chuẩn đánh giá chất lượng cơ sở giáo dục được áp dụng từ bộ tiêu chuẩn đánh giá chất lượng giáo dục cấp cơ sở đào tạo của tổ chức $\mathrm{AUN}-\mathrm{QA}$.

Trường Đại học Công nghiệp Thành phố Hồ Chí Minh xác định đảm bảo chất lượng là một hoạt động hết sức quan trọng của nhà trường. Nhằm hiện thực tầm nhìn của nhà trường "trở thành trường đại học ngang tầm với các nước tiến tiến trong khu vực về lĩnh vực đào tạo nhân lực chất lượng cao", năm 2017, Ban giám hiệu nhà trường quyết định đánh giá chất lượng giáo dục cấp cơ sở giáo dục theo tiêu chuẩn $\mathrm{AUN}-\mathrm{QA}$. Đây là một bước đi thể hiện sự quyết tâm của lãnh đạo nhà trường đối với công tác đảm bảo chất lượng trong giáo dục, mang đến cho sinh viên các chương trình đào tạo có chất lượng ngang tầm khu vực.

Bài báo này nghiên cứu và xác định hướng đi của Trường Đại học Công nghiệp Thành phố Hồ Chí Minh trong giai đoạn chuyển mình từ giai đoạn kiểm định chất lượng giáo dục theo tiêu chuẩn của Bộ Giáo dục năm 2016 sang đánh giá chất lượng giáo dục cấp cơ sở đào tạo theo tiêu chuẩn AUN - QA năm 2020.

\section{NỘI DUNG}

\subsection{Công tác đảm bảo chất lượng ở Trường Đại học Công nghiệp Thành phố Hồ Chí Minh}

Kể từ khi được nâng cấp thành trường Đại học vào năm 2004, Trường Đại học Công nghiệp Thành phố Hồ Chí Minh luồn quan tâm đến công tác đảm bảo chất lượng trong giáo dục. Trường đã thành lập ban ISO từ rất sớm và vận hành hệ thống quản lí theo tiêu chuẩn quốc tế ISO 9001:2000. Năm 2008 Trường xác định tầm nhìn, sứ mạng của Trường trong công tác giáo dục và đào tạo, xác hướng đi của nhà trường là theo định hướng ứng dụng và ban hành chính sách chất lượng và mục tiêu chất lượng của trường. Đến năm 2010 hệ thống văn bản ISO được cập nhật theo phiên bản 9001:2008. Trường đã có hai đợt đánh giá nội bộ lần 8 và đánh giá nội bộ lần 9 theo phiên bản này. Đồng thời Trường cũng được tổ chức TUV của Cộng hòa liên bang Đức chứng nhận đạt chuẩn theo ISO có thời hạn từ năm 2011 - 2014. Song song với việc thực hiện đảm bảo chất lượng theo ISO, trường đã tích cực thực hiện việc tự đánh giá theo các tiêu chuẩn kiểm định chất lượng giáo dục. Năm 2009, trường $\mathrm{ĐH} \mathrm{CN} \mathrm{Tp} \mathrm{Hồ} \mathrm{Chí} \mathrm{Minh} \mathrm{là} \mathrm{một} \mathrm{trong} \mathrm{những} \mathrm{trường} \mathrm{Đại} \mathrm{học}$ đầu tiên tiến hành công tác tự đánh giá và gởi báo cáo tự đánh giá về Bộ giáo dục. Đến 2014, Trường lại tiếp tục thực hiện công tác tự đánh giá sau 5 năm và năm 2016, Trường Đại học Công nghiệp vinh dự là Trường Đại học đầu tiên ở khu vực phía nam và là Trường Đại học thứ 5 trong cả nước được chứng nhận đạt tiêu chuẩn kiểm định chất lượng giáo dục đại học cấp cơ sở.

Không dừng lại ở đó, tiếp nhận xu thế phát triển của công tác đảm bảo chất lượng của khu vực và trên thế giới, Đầu năm 2017, Trường Đại học Công nghiệp Tp Hồ Chí Minh đã đăng kí và được chấp nhận trở thành thành viên liên kết với tổ chức $\mathrm{AUN}-\mathrm{QA}$, tổ chức đảm bảo chất lượng của mạng lưới các trường Đại học Đông nam á. Trường đã đặt mục tiêu đến năm 2023 toàn bộ các chương trình đào tạo của trường đều được đánh giá hoặc kiểm định theo chuẩn khu vực $(\mathrm{AUN}-\mathrm{QA})$ hoặc chuẩn quốc tế (ABET) trong đó có 4 chương trình sẽ được tổ chức $\mathrm{AUN}-\mathrm{QA}$ đánh giá vào tháng 6 năm 2018.

\subsection{Lợi thế của Trường khi đánh giá chất lượng giáo dục cấp cơ sở giáo dục theo tiêu chuẩn $\mathrm{AUN}$ - QA} Trường Đại học Công nghiệp Thành phố Hồ Chí Minh chủ trương đánh giá chất lượng giáo dục cấp cơ sở giáo dục theo tiêu chuẩn AUN - QA sau khi đã được chứng nhận đạt tiêu chuẩn kiểm định chất lượng cấp cơ sở giáo dục của Bộ Giáo dục. Đồng thời từ quá trình phát triển công tác đảm bảo chất lượng giáo dục của nhà trường có thể xác định một số lợi thế sau đây

\subsubsection{Trường Đại học Công nghiệp có bề dày về công tác đảm bảo chất lượng}

Có thể nói ngay từ khi thành lập và trong suốt quá trình hoạt động, trường Đại học Công nghiệp Thành phố Hồ Chí Minh luôn chú trọng đến công tác đảm bảo chất lượng. Điều này đã giúp hình thành ý thức đảm bảo chất lượng trong đại đa số cán bộ giảng viên, công nhân viên của nhà trường. Đây là một thuận lợi vô cùng to lớn giúp nhà trường dễ dàng nhận được sự đồng thuận và đồng lòng trong việc thực hiện công tác đảm bảo chất lượng từ tất cả cán bộ giảng viên và công nhân viên của nhà trường.

Bề dày về công tác đảm bảo chất lượng còn giúp cho cán bộ giảng viên, công nhân viên của trường tích lũy kinh nghiệm trong lĩnh vực đảm bảo chất lượng. Cán bộ, giảng viên, công nhân viên của trường có được kiến thức nền tảng về công tác đảm bảo chất lượng, có khả năng nhạy bén và dễ dàng tiếp cận với những đổi mới trong công tác đảm bảo chất lượng.

2.2.2. Trường Đại học Công nghiệp Thành phố Hồ Chí Minh có nhiều hoạt động đáp úng yêu cầu của công tác đảm bảo chất lự̛ng

Từ yêu cầu của việc kiểm định chất lượng và đảm bảo chất lượng trong giáo dục đại học, Trường Đại học 
Công nghiệp Thành phố Hồ Chí Minh đã thành lập Phòng Khảo thí và Đảm bảo chất lượng vào năm 2011 và quyêt định thành lập hội đồng đảm bảo chất lượng vào năm 2015. Phòng Khảo thí và Đảm bảo chất lượng đã tham mưu cho hội đồng đảm bảo chất lượng của Trường tổ chức nhiều hoạt động nhằm đáp ứng các yêu cầu của công tác đảm bảo chất lượng.

Nhà trường đã cử nhiều lượt cán bộ giảng viên tham gia các đọt tập huấn về đổi mới phương pháp giảng dạy ở trong và ngoài nước. Cán bộ giảng viên của nhà trường còn được tham gia các khóa học về công tác đảm bảo chất lượng do các tổ chức trong và ngoài nước tổ chức. Nhà trường khuyến khích và tạo điều kiện cho cán bộ giảng viên công nhân viên được học tập, nâng cao trình độ chuyên môn từ đó nâng cao năng lực, hiệu quả và chất lượng cộng viêc.

Công tác đảm bảo chất lượng trong đào tạo được chú trọng từ khâu xây dựng chương trình đào tạo, tổ chức đào tạo, cho đến các hoạt động kết nối doanh nghiệp, tư vấn hỗ trợ việc làm và kết nối với cựu sinh viên sau khi ra trường. Trường đã xây dựng nhiều hoạt động nhằm tăng tỷ lệ tốt nghiệp, tăng tỷ lệ có việc làm của sinh viên sau khi tốt nghiệp, giảm thời gian tốt nghiệp trung bình của sinh viên và giảm tỷ lệ sinh viên thôi học qua các năm.

Công tác nghiên cứu khoa học và phục vụ cộng đồng của giảng viên và sinh viên được quan tâm, thúc đẩy. Nhà trường luôn dành một phần kinh phí thõa đáng để hỗ trợ cho các hoạt động này. Tạo môi trường thuận lợi và động lực để giảng viên và sinh viên thực hiện các hoạt động nghiên cứu khoa học và phục vụ cộng đồng.

Nhà trường định kì thực hiện các khảo sát về các bên liên quan về các mặt hoạt động của trường đển đánh giá mức độ hài lòng của các bên liên quan và có cơ sở cải thiện chất lượng của các hoạt động trong nhà trường. Các khảo sát được tiến hành theo một quy trình chung và kết quả khảo sát được xử lí theo một quy trình khác. Các kết quả khảo sát sau khi xử lí được gởi đến các bộ phận liên quan và lưu trữ trong cơ sở dữ liệu của Phòng Khảo thí và Đảm bảo chất lượng.

Các hoạt động nêu trên đã cho phép nhà trường có cơ sở tốt hơn trong việc đăng kí đánh giá chất lượng giáo dục cấp cơ sở đào tạo với các tổ chức kiểm định trong và ngoài nước nói chung và tổ chức $\mathrm{AUN}-\mathrm{QA}$ nói riêng.

2.2.3. Trường Đại học Công nghiệp Thành phố Hồ Chí Minh có hệ thống minh chứng về công tác đảm bảo chất luợng phong phú

Ngoài việc thực hiện báo cáo tự đánh giá và đăng kí kiểm định chất lượng giáo dục cấp cơ sở giáo dục vào năm 2015, Trường còn có 23 chương trình đang xây dựng theo tiêu chuẩn đảm bảo chất lượng $\mathrm{AUN}-\mathrm{QA}$ và 11 chương trình xây dựng theo chuẩn $\mathrm{ABET}$.

Để làm được điều này, các phòng ban chức năng và các đơn vị đào tạo đã có ý thức và kinh nghiệm trong việc thu thập, phân loại và lưu trữ minh chứng. Các hoạt động diễn ra ở trường đều có minh chứng kèm theo được lưu giữ lại ở các bộ phận liên quan.

Đây là một thuận lợi rất có ý nghĩa trong việc theo thực hiện công tác đảm bảo chất lượng vì nếu không có minh chứng thì không thể đánh giá được công tác đảm bảo chất lượng.

Do đó, để tiến hành đánh giá công tác đảm bảo chất lượng cấp cơ sở giáo dục theo tiêu chuẩn $\mathrm{AUN}-\mathrm{QA}$, nhà trường đã có sẵn kho minh chứng để sàng lọc và lựa chọn những minh chứng phù hợp với các tiêu chí của bộ tiêu chuẩn và chỉ cần thu thập thêm các minh chứng còn thiếu chứ không cần phải đi thu thập và xây dựng toàn bộ hệ thống minh chứng theo yêu cầu.

2.2.4. Trường Đại học Công Nghiệp Thành phố Hồ Chí Minh có kinh nghiệm trong việc viết báo cáo tự đánh giá

Trường đã có kinh nghiệm hai lần viết báo cáo tự đánh giá đảm bảo chất lượng cấp cơ sở. Ngoài ra, cán bộ của trường đã được tập huấn nhiều cho việc viết báo cáo tự đánh giá cấp chương trình. Do đó có thể nói, đội ngũ cán bộ của nhà trường có kinh nghiệm trong việc báo cáo tự đánh giá. Đồng thời, trong trường có nhiều cán bộ đã trải qua việc viết báo cáo tự đánh giá nên nhà trường có thể lựa chọn được đội ngũ viết báo cáo tự đánh giá cho trường là những người có kinh nghiệm và có khả năng viết tốt.

Đây là một thuận lợi quan trọng vì báo cáo tự đánh giá thể hiện kết quả đạt được của nhà trường khi đánh giá chất lượng giáo dục của cơ sở mình theo tiêu chuẩn $\mathrm{AUN}-\mathrm{QA}$. Báo cáo đánh giá được viết tốt sẽ giúp cho các đánh giá viên có cảm nhận tốt hơn và hiểu rõ hơn về các hoạt động của nhà trường. Đồng thời báo cáo tự đánh giá tốt giúp bộc lộ tốt hơn các thế mạnh của nhà trường. Việc này sẽ giúp cho trường đạt được điểm số cao hơn trong kì đánh giá chất lượng do tổ chức AUN - QA thực hiện. 


\subsection{Những thách thức trong công tác đảm bảo chất lượng cấp cơ sở đào tạo theo tiêu chuẩn $\mathrm{AUN}-\mathrm{QA}$}

2.3.1. Đánh giá chất luợng cấp cơ sở đào tạo đòi hỏi sụ phối hợp đồng bọ của tất cả các đơn vị trong nhà trường

Bộ tiêu chuẩn đánh giá chất lượng giáo dục của AUN - QA gồm 25 tiêu chuẩn với 111 tiêu chí đánh giá tất cả các hoạt động trong nhà trường bao gồm: Đảm bảo chất lượng về mặt chiến lược, đảm bảo chất lượng về mặt hệ thống, đảm bảo chất lượng về mặt chức năng và đảm bảo chất lượng về mặt kết quả. Trong đó các tiêu chuẩn đảm bảo chất lượng về mặt chức năng bao gồm: Đảm bảo chất lượng trong các hoạt động đào tạo, hoạt động nghiên cứu khoa học và hoạt động phục vụ cộng đồng. Các hoạt động đảm bảo chất lượng cần được đánh giá liên quan đến hoạt động của tất cả các phòng ban chức năng và các đơn vị đào tạo trong nhà trường và cũng yêu cầu đánh giá sự đồng bộ giữa các phòng ban và các đơn vị đào tạo. Điều này đòi hỏi phải có sự phối hợp chặt chẽ giữa các đơn vị trong nhà trường và sự triển khai đồng bộ các chính sách của nhà trường ở tất cả các đơn vị.

Đối với Trường Đại học Công nghiệp Thành phố Hồ Chí Minh, Hiện nay có đến 19 đơn vị đào tạo với hơn 36.000 sinh viên thì việc triển khai một cách đồng bộ và nhất quán các hoạt động và chính sách của trường tại các đơn vị là một vấn đề khó khăn. Điều này đòi hỏi phải có kế hoạch rất chi tiết, phải có tập huấn và triển khai một cách đồng bộ đồng thời phải có các hoạt động giám sát, kiểm tra để đảm bảo các hoạt động diễn ra một cách đồng bộ nhịp nhàng.

Để thể hiện sự phối hợp chặt chẽ và sự triển khai đồng bộ các chính sách và hoạt động của nhà trường ở tất cả các đơn vị, cần phải thu thập một cách đầy đủ hệ thống minh chứng của các hoạt động được triển khai ở từng đơn vị. Các minh chứng này cần được tổng hợp và trình bày một cách khoa học và có hệ thống và phải được lưu trữ sao có các bộ phận liên quan dễ dàng kiểm soát và truy xuất được.

2.3.2. Quan điểm về đảm bảo chất lượng của $\mathrm{AUN}$ - QA khác với quan điểm về kiểm định chất lượng mà trường đã thực hiện trước đây

Trường Đại học Công nghiệp Thành phố Hồ Chí Minh đã đăng kí kiểm định và đạt chứng nhận đạt tiêu chuẩn kiểm định chất lượng giáo dục cấp cơ sở năm 2016. Mặt dù cả hai bộ tiêu chuẩn cùng đánh giá việc đảm bảo chất lượng trong các hoạt động của nhà trường như chiến lược, nhân sự, đào tạo, nghiên cứu khoa học, phục vụ cộng đồng, tài chính...Tuy nhiên mỗi bộ tiêu chuẩn về đảm bảo chất lượng tập trung đánh giá các khía cạnh khác nhau của các hoạt động đó. Điều này thể hiện các quan điểm khác nhau của các bộ tiêu chuẩn.

Do đó, không thể áp dụng một cách máy móc các kết quả đã đạt được ở lần kiểm định trước để đánh giá chất lượng giáo dục theo bộ tiêu chuẩn $\mathrm{AUN}-\mathrm{QA}$. Khi viết báo cáo tự đánh giá chất lượng theo tiêu chuẩn AUN - QA, cần phải tập trung tìm hiểu về quan điểm của $A U N$ - QA về đảm bảo chất lượng. Báo cáo tự đánh giá phải thể hiện được sự đáp ứng của các hoạt động của nhà trường đối với bộ tiêu chuẩn $\mathrm{AUN}$ QA. Điều này đồng nghĩa với việc cần phải viết báo cáo tự đánh giá với một cách nhìn, cách thể hiện hoàn toàn mới. Không nên phát triển báo cáo tự đánh giá trên nền báo cáo cũ và cũng không nên dùng báo cáo tự đánh giá cũ như một tài liệu tài liệu tham khảo.

Mặt dù các hoạt động được đánh giá theo tiêu chuẩn AUN - QA tương tự như các hoạt động được kiểm định vào 2016, nhưng các tiêu chuẩn đánh giá là không giống nhau. Do đó, không thể dùng tất cả các minh chứng đã thu thập được trong để làm minh chứng để đánh giá theo tiêu chuẩn $\mathrm{AUN}-\mathrm{QA}$ và các minh chứng sẵn có này cần được sắp xếp và tổ chức lại cho phù hợp với các yêu cầu của bộ tiêu chuẩn mới. Ngoài ra, cần phải thu thập thêm các minh chứng khác theo yêu cầu của bộ tiêu chuẩn.

2.3.3. Ngôn ngữ sử dụng trong đánh giá theo tiêu chuẩn của $\mathrm{AUN}-\mathrm{QA}$

Ngôn ngữ được sử dụng trong đánh giá chất lượng theo tiêu chuẩn AUN - QA là tiếng Anh. Đây là ngôn ngữ thứ hai và chưa được sử dụng phổ biến trong hoạt động hàng ngày tại Trường Đại học Công nghiệp Thành phố Hồ Chí Minh. Do đó điều này dẫn đến các khó khăn sau:

Khi viết báo cáo tự đánh giá, người viết khó diễn đạt được toàn bộ ý tưởng của mình bằng tiếng Anh, nên không thể hiện được tất cả các thế mạnh của trường. Người viết cũng có thể mắc một số lỗi diễn đạt, điều này làm cho đánh giá viên khó hiểu hoặc hiểu nhầm. Vì vậy, báo cáo tự đánh giá trông không tốt bằng các hoạt động thực sự của trường. Các đánh giá viên đọc báo cáo tự đánh giá sẽ không đánh giá đúng các thành tựu của nhà trường và không có được ấn tượng tốt về việc đảm bảo chất lượng của trường.

Trong quá trình đánh giá ngoài, ngôn ngữ được sử dụng là tiếng Anh. Tuy nhiên không phải tất cả các bên liên quan tham gia phỏng vấn đều cảm thấy thoải mái trong giao tiếp bằng tiếng Anh. Do đó, trong quá 
trình giao tiếp cũng có thể dẫn đến hiểu nhầm và không thể hiện được hết các thế mạnh của trường. Nếu sử dụng biện pháp mời phiên dịch thì phải dành một nửa thời gian phỏng vấn cho việc phiên dịch. Dẫn đến các đánh giá viên sẽ không thể đặt nhiều câu hỏi và khám phá được các thế mạng của trường.

\subsection{Giải pháp}

Trên cơ sở các thuận lợi và khó khăn được phân tích ở trên, xét tình hình thực tế của trường và bộ tiêu chuẩn đánh giá của $\mathrm{AUN}-\mathrm{QA}$, một số giải pháp sau đây có thể áp dụng để đảm báo chất lượng giáo dục. Các giải pháp này không chỉ có thể khắc phục các khó khăn mà còn giúp triển khai hoạt động tự đánh giá phù hợp với điều kiện thực tế của nhà trường.

\subsubsection{Thành lập hội đồng đảm bảo chất lương và tổ thu ki đảm bảo chất lương}

Hội đồng đảm bảo chất lượng được thành lập gồm có Hiệu trưởng làm chủ tịch hội đồng các thành viên còn lại trong ban giám hiệu là các phó chủ tịch và các trưởng đơn vị trong trường là ủy viên. Hội đồng họp ra quyết định thành lập các ban chuyên trách phụ trách các nhóm tiêu chuẩn liên quan trực tiếp đến đơn vị của mình và thống nhất kế hoạch hành động nhằm đảm bảo chất lượng cấp cơ sở đào tạo. Sau khi hội đồng đã thống nhất kế hoạch, các ban chuyên trách chịu trách nhiệm triển khai kế hoạch này. Phòng KT\&ĐBCL được giao nhiệm vụ điều phối, theo dõi và báo cáo kết quả thực hiện kế hoạch lên Hội đồng.

Tồ thư kí được thành lập từ nhân sự của tổ đảm bảo chất lượng của tất cả các đơn vị trong trường. Mỗi thư kí trong tổ được giao nhiệm thu thập, sắp xếp, xử lí và lưu trữ minh chứng ở tại đơn vị mình và báo cáo về cho phòng KT\&ĐBCL. Phòng KT\&ĐBCL có trách nhiệm tổng hợp các minh chứng từ các thư kí trong tổ và báo cáo lên hội đồng.

Việc phân công công việc như trên đảm bảo các hoạt động đảm bảo chất lượng sẽ được tiến hành đồng bộ và nhất quán ở các đơn vị, đồng thời đảm bảo sự phối hợp chặt chẽ giữa các đơn vị, phòng ban trong nhà trường. Giải pháp này cũng sẽ đảm bảo các minh chứng sẽ được thu thập một cách đầy đủ, kịp thời, được tổng hợp, sắp xếp và lưu trữ một cách khoa học.

\subsubsection{Xây dưng cơ sở dũ liệu đảm bảo chất lượng chung của toàn truờng}

Nhằm mục đích kiểm soát chất lượng và thuận lợi trong việc lập kế hoạch cải thiện, cần xây dựng cơ sở dữ liệu đảm bảo chất lượng chung của toàn trường. Cơ sở dữ liệu này là các minh chứng thứ cấp, bao gồm các số liệu thống kê đã qua xử lý như: số lượng sinh viên tuyển sinh qua mỗi năm, tỷ lệ tốt nghiệp và thôi học của từng khóa, tỷ lệ sinh viên ra trường có việc làm, số lượng cán bộ giảng viên mồi năm, trình độ của đội ngũ qua các năm, số lượt cán bộ, giảng viên được cử đi học hàng năm, số công trình khoa học của sinh viên và của đội ngũ cán bộ giảng viên hằng năm, chỉ số hài lòng của các bên liên quan đối với các hoạt động của nhà trường, chỉ số hài lòng của các bên liên quan đối với các đơn vị trong nhà trường.Cơ sở dữ liệu này được cập nhật định kì bởi các đơn vị liên quan và có thể được truy cập trong phạm vi toàn trường.

Việc tạo ra cơ sở dữ liệu trên có vai trò hết sức quan trọng vì nó cho phép giám sát được các chỉ số đảm bảo chất lượng tại bất kì thời điểm nào, cho phép theo dõi sự thay đổi của các chỉ số trên theo thời gian để nhận định về xu hướng phát triển của mỗi chỉ số. Cơ sở dữ liệu này còn cho phép kiểm soát chất lượng trong nhà trường và giúp nhà trường xác định dễ dàng các yếu tố cần cải tiến.

Việc xây dựng cơ sở dữ liệu còn giúp cho công tác đảm bảo chất lượng trở nên chuyên nghiệp hơn, thể hiện sự phối hợp chặt chẽ và đồng bộ giữa các đơn vị. Ngoài ra, cơ sở dữ liệu cũng sẽ giúp cho mỗi đơn vị dễ dàng tiếp cận với các thông tin của các đơn vị khác, tạo sự liên thông, liên kết tốt giữa các đơn vị với nhau. 2.4.3. Sư dụng các công cu triển khai để hỗ trợ việc viết báo cáo tư đánh giá

Báo cáo tự đánh giá là một văn bản mô tả mức độ đáp ứng các tiêu chí, tiêu chuẩn của cơ sở đào tạo đối với một bộ tiêu chuẩn đảm bảo chất lượng nào đó. Một báo cáo tự đánh giá tốt phải thể hiện được tất cả các điểm mạnh của cơ sở ở từng tiêu chí. Để làm được điều này, người viết báo cáo không những phải am hiểu về tất cả các hoạt động của nhà trường và còn phải có trong tay tất cả các minh chứng liên quan. Bộ tiêu chuẩn của AUN - QA gồm 25 tiêu chuẩn với 111 tiêu chí. Nếu chỉ giao trách nhiệm cho một người viết báo cáo tự đánh giá thì sẽ rất khó để viết đầy đủ thế mạnh của nhà trường đối với tất cả các tiêu chí và đưa ra các minh chứng phù hợp cho từng tiêu chí. Nếu phân công cho nhiều người viết thì khó kiểm soát được sự thống nhất về mặt ý tưởng và cách hành văn. Ngoài ra, tập hợp minh chứng cho tất cả các tiêu chí của bộ tiêu chuẩn này sẽ rất đồ sộ, vấn đề kiểm soát toàn bộ minh chứng để đưa ra những minh chứng có giá trị nhất cho mỗi tiêu chí cũng là một thách thức đối với đội ngũ viết báo cáo tự đánh giá. Dùng các công cụ triển khai hỗ trợ viết báo cáo tự đánh giá sẽ giúp khắc phục được các khó khắn trên.

Công cụ 1: Bảng thống kê minh chứng 


\section{BẢNG THỐNG KÊ MINH CHỨNG CHO TỪNG TIÊU CHÍ}

\begin{tabular}{|c|c|c|c|c|c|}
\hline $\begin{array}{c}\text { Tiêu } \\
\text { chuẩn }\end{array}$ & $\begin{array}{c}\text { Tiêu } \\
\text { chí }\end{array}$ & $\begin{array}{c}\text { Câu hỏi chẩn } \\
\text { đoán }\end{array}$ & $\begin{array}{c}\text { Minh chứng cần } \\
\text { có }\end{array}$ & Minh chứng hiện có & Kế hoạch cải thiện \\
\hline $\begin{array}{c}\text { Tiêu } \\
\text { chuẩn }\end{array}$ & $\begin{array}{c}\text { Tên } \\
\text { tiêu chí }\end{array}$ & $\begin{array}{c}\text { Câu hỏi chẩn } \\
\text { đoán }\end{array}$ & $\begin{array}{c}\text { Nêu những minh } \\
\text { chứng cần có đề } \\
\text { đáp ứng yêu cầu } \\
\text { của tiêu chí }\end{array}$ & $\begin{array}{c}\text { Nêu những minh chứng } \\
\text { hiện có tại trường }\end{array}$ & $\begin{array}{c}\text { Các minh chứng cần thu } \\
\text { thập, bồ sung tiếp theo }\end{array}$ \\
\hline
\end{tabular}

\section{Lưu ý}

* Nội dung

- Phân tích kỹ nội hàm của tiêu chí để xác định câu hỏi chuẩn đoán.

- Thông tin cần thiết để trả lời câu hỏi chẩn đoán $\rightarrow$ Xác định Minh chứng cần có

\section{Kỹ thuật xây dựng câu hỏi chẩn đoán}

- Nên chia thành các ý nhỏ, trả lời các câu hỏi cụ thể: Ai, Cái gì, Ở đâu, Lúc nào, Bao nhiêu? Trong đó lưu ý đến sự tham gia của các bên liên quan, quy trình thực hiện, những minh chứng của khâu thực hiện, kiểm tra và cải thiện trong quy trình PDCA.

- Các câu hỏi "Như thế nào?" nên tập trung vào sự đáp ứng, sự phù hợp với yêu cầu của các bên liên quan, tập trung vào xu hướng, tác động, hiệu quả.

- Các câu hỏi “Tại sao?" có thể được đặt ra trong nội bộ khi cần phải lí giải cho một vấn đề nào đó.

- Lưu ý đến các minh chứng đối sánh (bên trong và bên ngoài)

Bảng thống kê minh chứng được gởi cho từng thư kí. Các thư kí phân tích nội hàm của các tiêu chuẩn mình phụ trách, xác định các minh chứng cần có và các minh chứng hiện có phục vụ được cho các tiêu chuẩn này. Trên cơ sở đó xác định kế hoạch cải thiện nhằm bổ sung các minh chứng còn thiếu. Thư kí gởi bản tổng hợp về cho bộ phận chuyên trách để thống kê và lập kế hoạch hành động. Sau khi kết thúc đợt triển khai kế hoạch hành động thư kí thống kê lại minh chứng để báo cáo. Quy trình này được tiến hành thường xuyên, liên tục nhằm bổ sung kịp thời các minh chứng còn thiếu.

Công cụ 2: Bảng kế hoạch tổng thể

\begin{tabular}{|c|c|c|c|c|c|c|c|}
\hline $\begin{array}{l}\text { Tiêu } \\
\text { chuẩn }\end{array}$ & $\begin{array}{l}\text { Tiêu } \\
\text { chí }\end{array}$ & $\begin{array}{l}\text { Câu hỏi } \\
\text { chẩn đoán }\end{array}$ & $\begin{array}{l}\text { Minh } \\
\text { chứng cần } \\
\text { có }\end{array}$ & $\begin{array}{l}\text { Minh } \\
\text { chứng } \\
\text { hiện có }\end{array}$ & $\begin{array}{l}\text { Phân tích } \\
\text { minh } \\
\text { chứng hiện } \\
\text { có }\end{array}$ & $\begin{array}{l}\text { Trả lò̀i câu } \\
\text { hỏi chẩn } \\
\text { đoán }\end{array}$ & $\begin{array}{l}\text { Kế } \\
\text { hoạch } \\
\text { hành } \\
\text { đông }\end{array}$ \\
\hline $\begin{array}{l}\text { Tên tiêu } \\
\text { chuẩn }\end{array}$ & $\begin{array}{l}\text { Tên tiêu } \\
\text { chí }\end{array}$ & $\begin{array}{l}\text { Liệt kê các } \\
\text { câu hỏi chẩn } \\
\text { đoán }\end{array}$ & $\begin{array}{l}\text { Nêu những } \\
\text { minh chứng } \\
\text { cần có để } \\
\text { đáp ứng yêu } \\
\text { cầu của tiêu } \\
\text { chí }\end{array}$ & $\begin{array}{l}\text { Nêu } \\
\text { những } \\
\text { minh } \\
\text { chứng } \\
\text { hiện có } \\
\text { tại trường }\end{array}$ & $\begin{array}{l}\text { Phân tích } \\
\text { tính đầy đủ, } \\
\text { tính chính } \\
\text { xác, rõ ràng } \\
\text { của các } \\
\text { minh } \\
\text { chứng hiện } \\
\text { có. } \\
\text { Phân tích } \\
\text { khả năng } \\
\text { hố trợ của } \\
\text { các minh } \\
\text { chứng hiện } \\
\text { có đối với } \\
\text { tiêu chí }\end{array}$ & $\begin{array}{l}\text { Viết câu trả } \\
\text { lời ngắn gọn } \\
\text { cho các câu } \\
\text { hỏi chẩn } \\
\text { đoán }\end{array}$ & $\begin{array}{l}\text { Các việc } \\
\text { cần triển } \\
\text { khai dể } \\
\text { hỗ trợ } \\
\text { cho các } \\
\text { tiêu chí }\end{array}$ \\
\hline
\end{tabular}

Bảng kế hoạch tổng thể này được gởi đến các trưởng đơn vị cùng với bảng thống kê minh chứng của các thư kí. Trưởng các đơn vị nghiên cứu nội hàm của các tiêu chuẩn mình phụ trách kết hợp với thông tin minh chứng do tổ thư kí tổng hợp để xây dựng bảng kế hoạch tổng thể. Bảng kế hoạch tổng thể được tập hợp và dùng để xây dựng kế hoạch hành động chung của toàn trường. Sau khi kế hoạch hành động được triển khai và có kết quả, các bảng thống kê minh chứng và bảng kế hoạch tổng thể được cập nhật và gởi về phòng 
KT\&ĐBCL. Phòng KT\&ĐBCL tổng hợp và làm báo cáo cho hội đồng, và gởi bảng tổng hợp này cho tổ viết báo cáo tự đánh giá. Tổ viết báo cáo tự đánh giá căn cứ vào các thông tin minh chứng, câu hỏi chẩn đoán trong bảng kế hoạch tổng thể để xây dựng báo cáo tự đánh giá. Trong quá trình viết, tổ viết báo cáo tự đánh giá có thể lựa chọn, sắp xếp các minh chứng đã có theo ý tưởng của mình hoặc có thể yêu cầu cấu trúc lại minh chứng, xây dựng các minh chứng thứ cấp từ các minh chứng sơ cấp đã có hoặc yêu cầu thu thập và bổ sung thêm các minh chứng cần thiết. Tổ thư kí chịu trách nhiệm đáp ứng các yêu cầu về minh chứng cho tổ viết báo cáo tự đánh giá.

\subsubsection{Tăng cường các hoạt động sử dụng tiếng Anh trong nhà trường}

Để nâng cao trình độ tiếng Anh của đội ngũ cán bộ giảng viên, trường đã có chủ trương mở các lớp học tiếng Anh miễn phí cho toàn bộ cán bộ giảng viên, nhân viên trong trường. Tuy nhiên, để phát triển khả năng sử dụng tiếng Anh, cần tăng cường thêm các hoạt động sử dụng tiếng Anh trong nhà trường như thành lập các câu lạc bộ, cử cán bộ giảng viên tham gia các buổi tập huấn, hội nghị, hội thảo sử dụng tiếng Anh, tăng cường công bố các bài báo trên các tạp chí quốc tế, tổ chức các hội nghị, hội thảo quốc tế tại trường và xúc tiến các chương trình trao đổi cán bộ giảng viên.

Các hoạt động này nếu được tổ chức thường xuyên sẽ giúp cho cán bộ giảng viên có phản xạ tốt hơn trong giao tiếp bằng tiếng Anh. Về lâu dài các hoạt động này sẽ giúp cho cán bộ giảng viên nhận thấy vai trò của việc sử dụng tiếng Anh trong công việc. Đây chính là động lực thúc đẩy cán bộ giảng viên học tập nâng cao trình độ ngoại ngữ.

\section{KẾT LUẬN}

Đăng kí đánh giá chất lượng cơ sở giáo dục theo tiêu chuẩn AUN - QA trong bối cảnh ở Việt Nam chưa có nhiều cơ sở được AUN - QA đánh giá cấp cơ sở giáo dục là một việc làm táo bạo, thể hiện quyết tâm hội nhập toàn cầu của Ban giám hiệu Trường Đại học Công nghiệp Thành phố Hồ Chí Minh. Xác định đúng các thuận lợi và khó khăn sẽ giúp đội ngũ làm công tác đảm bảo chất lượng của trường đánh giá được khoản cách giữa vị trí hiện tại và đích đến của mình. Từ các thuận lợi và khó khăn được xác định ở trên cho thấy chúng ta hoàn toàn có thể đáp ứng yêu cầu đảm bảo chất lượng cấp cơ sở đào tạo theo tiêu chuẩn AUN - QA nếu chúng ta nỗ lực hết sức và tập trung làm việc với quyết tâm cao. Các giải pháp đề xuất là hoàn toàn khả thi và có thể áp dụng ngay trong quá trình triển khai đánh giá chất lượng cấp cơ sở giáo dục theo tiêu chuẩn AUN - QA. Triển khai các giải pháp này sẽ góp phần khắc phục các khó khăn của nhà trường và giúp cho việc đánh giá chất lượng theo tiêu chuẩn $\mathrm{AUN}$ - QA được diễn ra thuận lợi hơn.

\section{TÀI LIỆU THAM KHẢO}

[1] ASEAN university network quality assuarance, (2017), Guide to AUN - QA assessment at institutional level, version 2.0, ASEAN University network.

[2] Ban chấp hành trung ương Đảng, Nghị quyết hội nghị trung uoong 8 khóa XI, 2013.

[3] Bộ Giáo dục và Đào tạo, Quyết định ban hành quy định về tiêu chuẩn đánh giá chất luợng truòng đại học, 2007.

[4] Bộ Giáo dục và Đào tạo, Thông tu ban hành quy định về kiểm định cơ sở đánh giá chất luợng truờng đại học, 2017.

Ngày nhận bài: 03/01/2018

Ngày chấp nhận đăng: 19.10/2018 